\title{
Effect of multiple washing operations on removal of heavy metals from an alkaline farmland soil and the strategy for agricultural reuse
}

\section{Xiaofang Guo}

Taiyuan University of Science and Technology

Yu Gao

Taiyuan University of Science and Technology

\section{Wei Han}

Taiyuan University of Science and Technology

\section{Guohui Zhao}

Taiyuan University of Science and Technology

\section{Guixiang Zhang ( $\nabla$ zhanggx@tyust.edu.cn )}

Taiyuan University of Science and Technology https://orcid.org/0000-0003-1673-6728

\section{Dandan Liu}

Taiyuan University of Science and Technology

\section{Research Article}

Keywords: alkaline farmed-land, multiple washing, mixed chelators, heavy metal, agricultural reuse

Posted Date: March 1st, 2022

DOI: https://doi.org/10.21203/rs.3.rs-1363916/v1

License: @ (i) This work is licensed under a Creative Commons Attribution 4.0 International License. Read Full License 


\section{Abstract}

Little study carried out the soil washing experiments using pot experiments to simulate in-situ soil washing operation, particularly for the alkaline soil. This study explored the effect of multiple washing operation using pot experiments on the removal efficiencies of heavy metals from the alkaline farmland soil and the reuse strategy of the washed soil for safe agricultural production. The results showed that the removal efficiencies of $\mathrm{Cd}, \mathrm{Pb}, \mathrm{Cu}$ and $\mathrm{Zn}$ after the seven times washing with the mixed chelator (EDTA, GLDA and citric acid) were $41.1 \%, 47.1 \%, 14.7 \%$ and $26.5 \%$, respectively, which were close to those from the results of EDTA treatment. For the alkaline soil studied, the 2nd washing with the mixed chelator most effectively removed heavy metals owing to the activation of heavy metals after the first washing operation. The mixed chelator more effectively increased the proportion of stable speciation of heavy metals and maintained soil nutrients such as nitrogen content in soil than EDTA did, indicating the little disturbance of alkaline soil quality after being washed by the mixed chelator. After application of amendment into the washed soil, there was no visible difference in biomass weight of crops from the soil washed with different agents, indicating that the inhibitory effect of both washing agents on the plant growth was effectively alleviated. The $\mathrm{Cd}$ and $\mathrm{Pb}$ in $Z$. may were below the threshold of Hygienical Standard for Feeds of China (GB 13078 - 2017) (1 and $30 \mathrm{mg} \cdot \mathrm{kg}^{-1}$ ). Moreover, after three times of cropping, the concentrations of available heavy metals in the soil washed with the mixed chelator were lower than those in the washed soil with EDTA, indicating the value and potential of agricultural reuse of alkaline farmland soil being washed with the mixed chelator here.

\section{Introduction}

The national survey of soil contamination in China reported that about $16.1 \%$ of the sampling sites was over the standard and one-sixth of the farmland was contaminated with heavy metals (Chen et al. 2014). Heavy metals were the primary pollutants to affect the soil environmental quality in China, particularly the farmland soil (State of China's Ecological Environment, 2021). Numerous studies have found that the potential risk of heavy metals in farmland soil is related to the soil properties, especially soil pH (Zeng et al., 2011; Orr et al., 2020; Mikel et al., 2022). When the levels of heavy metals in alkaline and acidic soils are comparable, the potential risk of heavy metals in the alkaline soil was lower than that in the acidic soil (Tang et al., 2015). Most researches on the remediation of heavy metals-contaminated soils focused on the acid soil and neutral soil (Ma et al., 2020; Wu et al., 2020; Jia et al., 2021). In fact, the alkaline soils that contaminated by toxic heavy metals should not be ignored because the high levels of heavy metals in the alkaline soils also have the negative impact on the growth and productivity of crops and health risk through food chain (Gluhar et al., 2019b; Wang et al., 2020b). Therefore, the remediation of alkaline soil contaminated with heavy metals also needs to be paid enough attention to ensure the enough and safe food production.

Various remediation strategies have been developed according to the immobilization mechanism (i.e., organic amendment, inorganic amendments) or removal mechanism (i.e., adsorption, complexation, ion exchange, chemical precipitation, oxidation-reduction) (Nejad et al. 2017; Beiyuan et al. 2018). Among the remediation measures, soil washing is one of the most efficiently chemical treatment techniques for removal of heavy metals from soil (Yoo et al. 2018). The chelating agents, especially Ethylenediaminetetraacetic acid (EDTA), had a high activity and removal of multiple heavy metals from soils with various pH values (Udovic et al., 2012; Manouchehri et al., 2006). Nevertheless, the removal of heavy metals from the alkaline soils by chelating agents was more difficult than acid soil (Alberto et al. 2015; Sun et al., 2020). For example, the removal percentage of $\mathrm{Pb}$ in the alkaline soil ( $828 \mathrm{mg} \cdot \mathrm{kg}^{-1}$ of Pb) by EDTA was $67 \%$, which was evidently lower than the removal percentage of $\mathrm{Pb}(80 \%)$ in the acidic soils $\left(673 \mathrm{mg} \cdot \mathrm{kg}^{-1} \mathrm{of} \mathrm{Pb}\right)$ by EDTA (Gluhar et al. 2019a). Therefore, it is necessary to take measures to improve the removal efficiencies of heavy metals from alkaline soils by chelating agents. 
It has been reported that various factors such as washing times, flow rate and composition of chelating agent were important for increasing removal efficiency of heavy metals from soils (Guo et al. 2018a; Liu et al. 2019; Yan et al. 2021). Our previous study found that multiple washing processes could promote the removal efficiencies of heavy metals from an alkaline-contaminated soil, particularly for the removal of $\mathrm{Cd}$, which was mainly due to the enough reaction time to activate heavy metals in soil (Guo et al., 2018a). Most of these soil washing studies were carried out in the ways of laboratory washing by stirring and shaking (Alberto et al., 2015). However, the shaking or stirring operations are generally not suitable for the remediation of large-scale farmland soil. The in-situ remediation methods for effective removal of heavy metals from alkaline farmland soil are urgently needed to ensure safe agricultural production in these soils.

The pot experiment is similar to in-situ soil washing operation, which is an important soil washing way to put soil washing technology into practice for field application (Hu et al., 2014; Zhai et al., 2018). Our previous research primarily focused on the acid soil and neutral soil remediation by the multiple washing operation using MC (the molar ratio of citric acid, EDTA, and $\mathrm{KCl}=10: 2: 3$ ). In addition, $\mathrm{Hu}$ et al. (2014) reported that the removal percentages of $\mathrm{Cd}, \mathrm{Cu}, \mathrm{Pb}$, and Zn via column leaching experiment (50 mM EDTA ) were $90 \%, 88 \%, 90 \%$, and 67\%, respectively. Nevertheless, further studies on the soil washing experiment using the pot experiment are needed to carry out to explore the removal efficiencies of heavy metals from soil under the condition of "in-situ" washing operation.

Besides removal efficiencies of heavy metals from alkaline farmland soil, another important consideration is soil productivity and food safety. Many studies have reported that EDTA is difficult to be degraded in the soil environment, which has negative role in soil function, soil nutrients, growth of plant, and agricultural production (Gluhar et al. 2020; Zhao et al. 2019; Jelusic et al. 2014; Kaurin et al. 2020; Guo et al. 2020a). Therefore, the mixed-chelators (MC) of EDTA and environment-friendly agents have aroused widespread interest in the remediation of heavy metals-contaminated soil in recent years for keeping the removal efficiencies of heavy metals and alleviating the negative effect of chelator on the soil function and properties (Peng et al. 2020; Thinh et al. 2020; Wang et al. 2020a). Recently, we also developed a kind of the mixed-chelators (the mixture of EDTA, GLDA, and citric acid with their molar ratio of 1:1:3), which obviously reduced the contents of $\mathrm{Pb}, \mathrm{Cu}$ and $\mathrm{Zn}$ by $34.5 \%, 24.6 \%$ and $10.7 \%$ from an alkaline soil, respectively (Guo et al. 2018b). Additionally, the mixed-chelator significantly decreased the negative effects of washing agents on soil properties and enzyme activities when compared with the EDTA did (Guo et al. 2018a). Similar results were also reported by several other studies (Wang et al., 2018a; Xue et al., 2019; Hazrati et al., 2020). Although some studies have reported that various mixed-chelators can effectively remove heavy metals from the acid and alkaline farmland soil (Wei et al., 2016; Guo et al., 2018a; Begum et al., 2020). However, the effect of the mixed-chelator of EDTA, GLDA, and citric acid on the removal efficiencies of heavy metals from an alkaline soil after multiple washing via pot experiment and the strategies of agricultural reuse after soil washing are still not fully developed and understood.

The primary objectives of this study were (1) to investigate the effects of the mixed-chelator of EDTA, GLDA, and citric acid on the removal efficiencies of heavy metals from an alkaline farmland soil using multiple washing operation under the static pot experiment condition; (2) to examine the key step of effective removal of heavy metals by the mixedchelator and to explore its mechanism; (3) to examine the changes in soil physico-chemical properties and crop productivity and safety after soil washing. The results of this study will be helpful for effectively remediating alkaline farmland soil contaminated with heavy metals and proposing the strategy of agricultural reuse in safe way after washing.

\section{Materials And Methods}

\subsection{Soil, washing agent, and plant}


The surface soil sample $\left(0-20 \mathrm{~cm}, 18.4 \%\right.$ of $\left.\mathrm{CaCO}_{3}\right)$ was collected from a derelict farmland around a metal smelter in Zhuzhou City (China, Hunan Province). Wiping out the plant roots and other debris in soil sample. The soil sample was air-dried at room temperature. The soil was grounded and passed through different sieves (2-mm and 0.149-mm) for subsequent experiments and analysis.

The mixed chelator (MC) was the mixture of EDTA, GLDA, and citric acid (molar ratio of 1:1:3). The pH value of each chelator solution was adjusted to 3.50 using the diluted $\mathrm{NaOH}$ and $\mathrm{HNO}_{3}$ solution. The Ethylenediaminetetraacetic acid (EDTA) and citric acid (analytical reagents grade) were purchased from Sinopharm Chemical Reagent Co., Ltd. The N, N-bis(carboxymethyl)glutamic acid (GLDA, relative molecular mass: 351.1, solid content: > 47\%, and density: 1.400 $\mathrm{g} \cdot \mathrm{cm}^{-3}$ ) was purchased from Akzo Nobel Chemicals Co., Ltd.

Z. mays (Yunshi-5) and Chinese cabbage were selected as representative crops to investigate the effects of soil washing on plant growth and the uptakes of heavy metals by shoots and roots.

\subsection{Experimental design}

The soil washing experiment was conducted in plastic pots (diameter $\times$ height $=9.5 \mathrm{~cm} \times 12.5 \mathrm{~cm}$ ). From the bottom to top, each pot was filled in a nylon mesh (200 mesh), quartz sand, and the air-dried soil $(1.1 \mathrm{~kg})$. The soil was kept with the field moisture by deionized water for one week. A plastic pot as washing devices was equipped over the plastic pot with soil. The flow velocity of washing agents was $1 \mathrm{~mL} \cdot \mathrm{min}^{-1}$. The trapping device for leachate collection was placed under the plastic pot with soil. The design of washing process is shown in Table 1 . The $1^{\text {st }}, 2^{\text {nd }}$ and $5^{\text {th }}$ washing used EDTA or MC solution $\left(0.1 \mathrm{~mol} \cdot \mathrm{L}^{-1}, 0.55 \mathrm{~L}\right)$, while the $3^{\text {rd }}, 4^{\text {th }}, 6^{\text {th }}$ and $7^{\text {th }}$ washing used deionized water $(0.55 \mathrm{~L})$. The control treatment was washed by deionized water $(0.55 \mathrm{~L})$ throughout the experiment. Each treatment was set up in triplicate.

After soil washing, the soil amendment was applied into soil to improve the physiochemical properties. According to our previous studies, the combination of inorganic and organic amendments $\left(0.2 \%\right.$ of $\mathrm{CaCO}_{3}$ and $2 \%$ of chicken manure) was thoroughly mixed with the washed soil because this amendment was favorable for the growth of plant (Guo et al. 2019; Yang 2019). The amended-soils were used to plant three-seasons crops. The first-season crop was Chinese cabbage. Ten Chinese cabbage seeds were sown in each pot. Two weeks later, just three young Chinese cabbages were retained. The each pot with Chinese cabbages was watered by deionized water every day (50-100 mL) to keep at $60 \%-70 \%$ of soil water holding capacity. After seven weeks, the aboveground (shoots) and underground (roots) parts of Chinese cabbage were harvested. The second- and third-season crop was $Z$. mays. Five seeds of $Z$. mays for the second-season crop were sown in each pot after harvesting Chinese cabbage. Two weeks later, just three $Z$. mays were retained. The each pot with $Z$. mays was watered by deionized water every day $(50-100 \mathrm{~mL})$ to maintain at $60 \%-70 \%$ of soil water holding capacity. After a month, Z. mays were harvested. The plant method of the third-season crop (Z. mays) was the same as the second-season crop.

\subsection{Collection and analysis of soil and plant samples}

The shoots and roots of plants were thoroughly washed by the deionized water. The fresh weight of shoots and roots were weighted after being wiped. After that, the plant samples were dried for $30 \mathrm{~min}\left(105^{\circ} \mathrm{C}\right)$, and then dried to constant weights at $65^{\circ} \mathrm{C}$ for $72 \mathrm{~h}$. The shoots and roots of plants were grounded, and then stored in a polyethylene bag for further analysis. The soil samples were destructively collected, and then air-dried at room temperature. The dried soil samples were grounded to pass through a $0.85-\mathrm{mm}$ sieves for further analysis. The soil properties $(\mathrm{pH}$, organic matter, cation exchange capacity, total and available nitrogen/phosphorus/potassium) were analyzed according to the methods in the book of Analytical Methods of Soil Agrochemistry (Lu 2000). 
The total concentrations of heavy metals $(\mathrm{Cd}, \mathrm{Pb}, \mathrm{Cu}$, and $\mathrm{Zn})$ in soil samples were determined by atomic absorption spectrometry (AAS, Hitachi Z-2300, Japan) after digestion with $\mathrm{HF}-\mathrm{HNO}_{3}-\mathrm{HClO}_{4}$. The speciation of heavy metals in soil samples was sequentially extracted according to Tessier et al. (1979). The available concentrations of heavy metals in soil were assessed by chemical extraction method using 1M ammonium acetate solution (Wang et al. 2018b). The plant samples ( $0.5 \mathrm{~g}$ aboveground part, or $0.1 \mathrm{~g}$ underground part) were digested with $\mathrm{HNO}_{3} / \mathrm{H}_{2} \mathrm{O}_{2}(5: 2 \mathrm{v} / \mathrm{v})(\mathrm{Hu}$ et al. 2014). After digestion, the solution was filtered through $0.45-\mu \mathrm{m}$ filters and diluted with deionized water. The concentrations of heavy metals in plant were determined by AAS (Wang et al. 2018b).

\subsection{Statistical analysis}

The statistical analysis of data was performed using SPSS 22.0 (SPSS Inc., Chicago, IL, USA). The data was presented as mean values \pm standard deviation (SD). Duncan's test at a significance level of $p \leq 0.05$ was used to test the differences between mean values.

\section{Results}

\subsection{The changes in soil properties after washing}

Soil washing significantly changed the soil physicochemical properties (Table 2). Soil pH increased 1.5 units after washing when compared with the control $(p<0.05)$. The CEC in soil after washing by $\mathrm{MC}$ significantly decreased by $5.5 \%$ and $8.3 \%$ when compared with the control and EDTA treatment, respectively $(p<0.05)$. In contrast, the EDTA treatment did not evidently change the CEC in soil when compared with the control. The nutrient such as total nitrogen, total and available potassium did not change obviously between soils that being washed with different washing agents. However, the organic matter, total phosphorus, available nitrogen and phosphorus in soil significantly increased after washing by MC. As compared with the control $(p<0.05)$, organic matter, available phosphorus and nitrogen in soil after being washed by $\mathrm{MC}$ increased by $5.1 \%, 43.4 \%$ and $65.9 \%$, respectively. As compared with EDTA treatment, total phosphorus and available nitrogen in soil after being washed by $\mathrm{MC}$ significantly increased by $42.9 \%$ and $55.6 \%$, respectively $(p<0.05)$. These results demonstrated that MC had more positive effect on soil physicochemical properties and soil nutrient than EDTA did.

\subsection{The removal efficiencies of heavy metals from the alkaline soil by multiple washing operation}

The removal efficiencies of heavy metals from alkaline soil were dependent on washing times (Fig. 1). The high removal efficiencies of heavy metals by MC were obtained at the first, second and fifth washing operations. The highest removal efficiencies of heavy metals by MC (8.8\%-23.8\%) was obtained at the second washing operation, which was similar to those by EDTA. There was significant difference between the removal efficiencies of all heavy metals by EDTA and MC after the two-step washing. As shown in Fig. 2, the total removal percentages of $\mathrm{Cd}$, $\mathrm{Pb}$ and $\mathrm{Cu}$ from soil by MC after the seven times washing were distinctly lower than those in EDTA washed soil $(p<0.05)$. The total removal percentages of $\mathrm{Zn}$ from soil by MC after the seven times washing were similar to those by EDTA $(p>$ 0.05). The removal efficiencies of $\mathrm{Pb}$ from soil by $\mathrm{MC}$ were evidently higher than other heavy metals.

\subsection{The fraction distribution of heavy metals in the alkaline soil after washing}

Soil washing significantly changed the fraction distribution of heavy metals in soil (Fig. 3). As compared with the control, each fraction of heavy metals in soil after being washed by MC was significantly decreased. For example, the carbonate-bound and Fe-Mn oxides-bound heavy metals decreased by $10.3 \%-68.2 \%$ and $47.7 \%-60.3 \%$, respectively. The organic matter-bound $\mathrm{Cu}$ decreased by $25 \%$. The exchangeable fraction of Cd significantly decreased, while the exchangeable fraction of $\mathrm{Pb}, \mathrm{Cu}$ and $\mathrm{Zn}$ slightly increased. 
The proportion of each $\mathrm{Cd}$ fraction in soil after being washed by $\mathrm{MC}$ was comparable to that in the soil after being washed by EDTA $(p>0.05)$. The carbonate-bound heavy metals in soil after being washed by MC were lower than those in soil after being washed by EDTA, particularly for the carbonate-bound Pb. Additionally, the proportion of residual fraction of $\mathrm{Cu}$ and $\mathrm{Zn}$ in soil by after being washed by MC were lower than those from the EDTA treatment. The heavy metals in soil after being washed were more stable than those in the original soil. Similar to EDTA, MC also effectively removed the active fractions of $\mathrm{Cd}$ and $\mathrm{Zn}$ from the alkaline soil.

\subsection{Plant growth and uptake of heavy metals by plant in the washed soil after amendment}

\subsubsection{Plant growth}

Table 3 lists the changes in biomass weight of Chinese cabbage and Z. may in soil after being washed by different types of washing agents. The biomass of Chinese cabbage, Z. may (batch 1), and Z. may (batch 2) in soil after being washed by MC was similar to that in soil after being washed by EDTA and the control $(p>0.05)$. Nevertheless, the biomass weight of $Z$. may in the second batchwas 2-3 times of that in the first batch.

\subsubsection{The uptakes of heavy metals by plants}

The concentrations of heavy metals in the shoots and roots of crops are listed in Table 3. According to Chinese Maximum Levels of Contaminants in Foods (GB 2762-2017), the concentrations of $\mathrm{Cd}$ and $\mathrm{Pb}$ in food should not exceed 0.2 and $0.3 \mathrm{mg} \cdot \mathrm{kg}^{-1}$, respectively. As shown in Table 3, the concentrations of $\mathrm{Cd}, \mathrm{Pb}, \mathrm{Cu}$ and $\mathrm{Zn}$ in Chinese cabbages in soil being washed by MC and EDTA were higher than those in the control. Especially, the concentrations of $\mathrm{Cd}$ and $\mathrm{Pb}$ in shoots (edible parts) of Chinese cabbage were $1.51-1.78 \mathrm{mg} \cdot \mathrm{kg}^{-1}$ and $0.62-0.74 \mathrm{mg} \cdot \mathrm{kg}^{-1}$, respectively, which exceeded the threshold of aforementioned standard. The concentrations of $\mathrm{Cd}, \mathrm{Pb}$ and $\mathrm{Cu}$ in shoots of Chinese cabbages from the MC treatment were comparable to those from the EDTA treatment $(p<0.05)$. The concentrations of $\mathrm{Cd}, \mathrm{Pb}, \mathrm{Cu}$ and $\mathrm{Zn}$ in roots significantly increased by $433.7 \%, 478.5 \%, 29.2 \%$ and $72.7 \%$ from the MC treatment as compared with those from the control, respectively $(p<0.05)$. However, the concentrations of $\mathrm{Pb}$ and $\mathrm{Cu}$ in roots of Chinese cabbages from the MC treatment were lower than those from the EDTA treatment, while the opposite was true for the other heavy metals.

The concentrations of $\mathrm{Cd}$ and $\mathrm{Zn}$ in roots and shoots of $\mathrm{Z}$. may (batch1) from the MC treatment were obviously lower than those from the control $(p<0.05)$. When compared with the control, The concentrations of $\mathrm{Cd}$ and $\mathrm{Zn}$ in roots of $Z$. may (batch1) decreased by $71 \%$ and $71 \%$, in shoots of $Z$. may (batch 1 ) decreased by $52 \%$ and $41 \%$, respectively. In addition, the concentration of $\mathrm{Cu}$ in the shoots of $Z$. may (batch1) from soil after being washed by MC were 2.8 times of those from the control. The $\mathrm{Pb}$ and $\mathrm{Cu}$ in all parts of $Z$. may (batch1) from MC treatment were similar to those from the EDTA treatment $(p>0.05)$. When compared with the control, the concentrations of $\mathrm{Cd}$ and $\mathrm{Pb}$ in the roots of $Z$. may (batch 2$)$ in the MC treatment significantly decreased $(p<0.05)$. When compared with the EDTA treatment, the concentrations of $\mathrm{Pb}$ in the roots and shoots of $Z$. may (batch 2) from the MC treatment were decreased by $49 \%$ and $57 \%$, respectively.

\subsubsection{Factors influencing on the uptakes of heavy metals by plants}

The different washing treatments had different effects on the availability of heavy metals in the alkaline soil (Fig. 4). For the MC treatment after harvest, the available heavy metals in soil first decreased, and then kept stable, which were higher than those in the soil from control. After the three-seasons planting, MC agent more effectively decreased the availability of $\mathrm{Cd}, \mathrm{Pb}$ and $\mathrm{Zn}$ in soil than EDTA treatment did $(p<0.05)$.

\section{Disccussion}




\subsection{Effect of soil washing on soil properties}

The increase in soil pH was mainly due to the residual of chelators in soil after washing operations (Zupanc et al. 2014a). The increases in available nitrogen and organic matter in soil were due to the introduction of nitrogen and carbon elements from the washing agents (Zupanc et al. 2014b). After washing, phosphorus in minerals could be dissolved and transformed to the form of available one (Guo et al. 2018b), which resulted in the increase in available phosphorus in soil. Furthermore, the citric acid could dissolve and transform insoluble minerals by proton dissociation, carboxyl coordination exchange, and reduction reaction to release nutrient elements, which contributed to the increase in availability of nutrients (Xiao et al. 2019). The little change of CEC in soil after being washed with EDTA was mainly due to the high introduction of $\mathrm{Na}^{+}$into soil. The lower CEC in soil after being washed by MC than that by EDTA and control treatment was most likely due to the less introduction of $\mathrm{Na}^{+}$and non-selective extraction of ions by $\mathrm{MC}$ (Chen et al. 2021). As compared with the results from our previous studies on alkaline soil properties with MC by stirring (soil-solution ratio of 1:2) (Guo et al. 2018a), the changes of soil properties and nutrients were relatively small here. The pot experiment after multiple washing operations extremely alleviated the change of alkaline soil properties.

\subsection{Effect of washing times on the removal efficiencies of heavy metals from the alkaline soil}

Among seven times washing, the relative high removal efficiencies of heavy metals by $\mathrm{MC}$ occurred at the first, second and fifth washing operations. The highest removal efficiencies of heavy metals occurred at the second washing, which was most likely attributed to the desorption of heavy metals from soil particles after the first washing (Yang et al 2016). Additionally, the competitive cations (e.g., $\mathrm{Ca}^{2+}, \mathrm{Mg}^{2+}, \mathrm{Na}^{+}, \mathrm{K}^{+}, \mathrm{Fe}^{2+}$ ) in the soil after first washing decreased, leading to the decrease in competition of above cations for the binding sites on the components of $\mathrm{MC}$ during the second washing (Polettini et al 2007; Finzgar et al 2007). Therefore, to effectively improve the removal efficiencies of heavy metals in the alkaline soil, it is necessary to activate heavy metals by multiple washing operations. The lower removal efficiencies of heavy metals from soil at the $3^{\text {rd }}-7^{\text {th }}$ washing operations than those at the $2^{\text {nd }}$ washing operation was most likely due to the following reasons: (1) the washing with deionized water only removed the residual chelates and weakly adsorbed chelates in soil (Jing et al. 2017); (2) there was the decrease in heavy metal contents and redistribution of heavy metal fractions after each washing (Xiao et al. 2019); (3) after the $5^{\text {th }}$ washing, organic matter bound and residual heavy metals in soil were activated and leached, resulting in a relatively dynamic equilibrium in the subsequent washing process.

The types of heavy metals played important role in their removal efficiencies, which was mainly due to their different complexing ability with chelators and different fraction distribution in the alkaline soil. For example, the stability constants of heavy metals with EDTA were 16.46 for $\mathrm{Cd}, 18.04$ for Pb, 18.80 for $\mathrm{Cu}$, and 16.50 for Zn (Jiang et al. 2003). The molecular of EDTA has several carboxyl functional groups, which can effectively activate the heavy metals that bounded on soil particles (Klik et al. 2021). The stability constants of citric acid and GLDA with Cd, Cu and Zn were 3.50 and 9.10, 5.90 and 10.50, and 6.21 and 10.00, respectively (Jiang et al. 2003). Evidently, the components of GLDA and citric acid in MC had relatively weaker complexing ability with heavy metals than EDTA did (Jean-Soro et al. 2012; Thinh et al. 2020). Therefore, the decrease in the amount of EDTA in MC resulted in the relatively lower removal efficiencies of heavy metals from the alkaline soil by MC than the EDTA treatment. The higher removal efficiencies of $\mathrm{Pb}$ and $\mathrm{Cu}$ from the alkaline soil by $\mathrm{MC}$ than other heavy metals was mainly due to the higher complexing ability of $\mathrm{Pb}$ and $\mathrm{Cu}$ with the components in $\mathrm{MC}$ than those of other heavy metals. Although the high content of $\mathrm{Zn}$ in the original soil and the strong covalently bonding between Zn and soil particle (Thinh et al. 2020), the MC had similar removal efficiency of $Z n$ to the EDTA did after several times washing. This finding was most likely due to the easy leaching of Zn-EDTA complexes from soil after several times washing (Qi et al. 2019). Meanwhile, the citric acid and GLDA in MC was also effective for the removal of $\mathrm{Zn}$ from the alkaline soil. 
As compared with the results from our previous studies on removal of heavy metals from acid soil by MC under pot washing condition (Guo et al. 2020b), the removal efficiencies of heavy metals from the alkaline soil by MC were higher than those from the acid soil. The finding indicates that multiple washing operation using MC agent was an effective way for effective removal of heavy metals from alkaline soil because of enough reaction time and washing ability for activating heavy metals in such type of soil.

\subsection{Effect of soil washing on the fraction distribution of heavy metals in the alkaline soil}

The stable fraction of heavy metals in the alkaline soil after being washed by MC increased (Fig. 3). The decrease in carbonate-bound and Fe-Mn oxides-bound heavy metals after being washed by MC was most likely due to that these fractions of heavy metals were sensitive to soil pH and easily being washed out by acidic agents (Zhao 2019). The percentages of residual $\mathrm{Cu}$ in soil were higher than those of organic matter-bound fraction of $\mathrm{Cu}$, which resulted in a low removal efficiency of Cu during washing. The crystal structure of residual fraction of heavy metals was hardly destroyed by EDTA, GLDA and citric acid agents because the heavy metals were tightly trapped in the mineral crystal structure (Xiao et al. 2019). The effective removal of the active Cd and Zn in the alkaline soil by MC contributed to the decrease in environmental risk and bioavailability of these heavy metals (Wang et al. 2018a). Nevertheless, a portion of stable heavy metals were activated after soil washing operations. The ligand bridges in soil between mineral surface and metal cations were formed after washing, which caused the re-adsorption of heavy metal-chelate complexes on the mineral surface (Chen et al. 2016; Guo et al. 2018a). It is consistent with the increase in the exchangeable fraction of $\mathrm{Pb}, \mathrm{Cu}$ and $\mathrm{Zn}$ in soil after being washed by MC. Moreover, the organic matter-bound $\mathrm{Cu}$ in the alkaline soil was activated by MC, which was most likely due to soil organic matter was washed during washing process (Liu et al. 2013).

The fraction distribution of heavy metals was different in the soils that being washed by MC and EDTA. (Fig. 3). Particularly, the more carbonate-bound $\mathrm{Pb}, \mathrm{Cu}$ and $\mathrm{Zn}$ in the alkaline soil from MC treatment than those from the EDTA treatment was mainly due to the easily extraction of carbonate-bound heavy metals by EDTA (Chen et al. 2015). Moreover, the lower proportions of residual $\mathrm{Cu}$ and $\mathrm{Zn}$ in the alkaline soil from MC treatment than those from EDTA treatments led to the increase in Fe-Mn oxides bounded $\mathrm{Zn}$ and exchangeable $\mathrm{Cu}$. Furthermore, the changes in fraction of heavy metals were related to various factors, especially the types of heavy metals, soil properties, and inorganic and organic colloid (Guo et al. 2020b).

\subsection{Effect of the washed soil after amendment on plant growth and plant uptakes of heavy metals}

When compared with the soil from control and EDTA treatment, the soil from MC treatment did not have evidently negative effect on the plant growth (Table 3). The biomass weight of $Z$. may in the second batchwas greater than that in the first batch, which was primarily due to the different available contents of heavy metals in soil (Guo et al. 2018b).

The heavy metals in the alkaline soil were activated after soil washing operations, particularly being washed by EDTA and GLDA (Wei et al. 2015), resulting in the easy uptakes of heavy metals by Chinese cabbage and Z. mays (Chaturvedi et al. 2019). The Chinese cabbage is a kind of leafy crops that has the higher transpiration rate than $Z$. mays, resulting in the easier transportation of heavy metals from soil to shoots of Chinese cabbage than Z. mays (Cheng et al. 2021). Additionally, the toxic effect of washing agents in soil can also promote phytoextraction of heavy metals. The EDTA had toxic effects on the plants because EDTA could enhance the destruction of plasma membrane and physiologic barrier of plant roots (Wang et al. 2021). With the increase of membrane effusion, the hazardous substances easily transport from roots to shoots through transpiration (Zhou et al. 2021). The GLDA and citric acid had a weakly negative influence on plasma membrane of plant, which benefited for GLDA-metal complexes absorbed by plant (Wu et al. 2015). Therefore, there were high levels of heavy metals in roots of Chinese cabbages from the MC 
treatment, especially $\mathrm{Pb}$ and $\mathrm{Cu}$. Simultaneously, the concentrations of $\mathrm{Cd}$ and $\mathrm{Pb}$ in the shoots (edible parts) of Chinese cabbage were exceeded the threshold of Chinese Maximum Levels of Contaminants in Foods (GB 27622017).

For the MC and EDTA treatments, the uptakes of heavy metals in the two batches of $Z$. mays had evident differences. On the one hand, it needed time for the inorganic and organic amendments to effectively improve the soil physiochemical properties (Spana et al. 2019; Yang et al. 2019). On the other hand, the plant uptakes of heavy metals were also related to the changes in proportion of available heavy metals in soil and the application of amendment (Guo et al. 2020a). After the soil being washed by MC, the concentrations of $\mathrm{Cd}$ and $\mathrm{Pb}$ in the shoots of Z. mays (two batch) were still below the threshold of the Standards of Feeds of China (GB 13078-2017) (Cd $<1 \mathrm{mg} \cdot \mathrm{kg}^{-1}, \mathrm{~Pb}^{2} 30 \mathrm{mg} \cdot \mathrm{kg}^{-}$ ${ }^{1}$ ). Therefore, the $Z$. mays (batch1 and batch2) from the soil after being washed by MC was safe for the use as feed production.

For the three-season crops, the concentrations of $\mathrm{Cu}$ and $\mathrm{Zn}$ in the shoots and roots of plants from both MC and EDTA treatment generally increased, which was mainly due to that the essential trace elements for crop growth could transport them into plants by the transport proteins on membrane surface (Liu et al. 2020). However, the non-essential elements $(\mathrm{Cd}, \mathrm{Pb})$ could be uptake by plant through binding with carboxyl uronic acid (Chen et al. 2021). The concentrations of heavy metals in roots were obviously higher than those in shoots was mainly attributed to that the compounds from the binding between heavy metals and ligand of root secretion were adsorbed and immobilized on the negatively charged cell wall of roots (Wei et al. 2015; Etesami et al. 2018; Yadav et al. 2018). Furthermore, the roots of $Z$. mays could effectively block the transport of heavy metals to its shoots, which could further explain the reason why the lower concentrations of heavy metals in shoots of $Z$. mays than those in shoots of Chinese cabbage (Cheng et al. 2021).

During planting, the lower available heavy metals in soil from MC treatment was most likely due to that the inhibition of acid secretion from plant roots by citric acid in MC, resulting in less activated heavy metals in MC-treated soil than those in other treatments ( $\mathrm{Li}$ et al. 2021). Therefore, the MC washing agent could effectively remediate the alkaline soil that was contaminated by heavy metals and benefited for the agricultural reuse of soil.

The correlations between the available heavy metals in soil and the contents of heavy metals in plants are showed in Fig. 5. There were positive correlations between the available $\mathrm{Cd}, \mathrm{Pb}, \mathrm{Cu}$ and $\mathrm{Zn}$ in soil before planting and heavy metals in roots and shoots of Chinese cabbage $(p<0.05)$. There were significant positive correlations between available $\mathrm{Pb}$ in soil before planting $Z$. mays (batch 1 ) and $\mathrm{Pb}$ in roots and shoots of $Z$. mays (batch 1$)(p<0.01)$. The available $\mathrm{Cu}$ and $\mathrm{Zn}$ in soil before planting Z. mays (batch 2) positively correlated with $\mathrm{Cu}$ and $\mathrm{Zn}$ in the roots and shoots of $Z$. mays (batch 2$)(p<0.01)$. These results showed that the available heavy metals in soil were easily transported from soil into the roots with plant growing and then to shoots, which improved the uptakes of heavy metals by plant, particularly by the roots (Shahid et al. 2012). Additionally, the uptakes of heavy metals by plant s were also related to the soil properties, plant physiological characteristics, and the bioavailability of heavy metals (Chen et al. 2021). Significantly negative correlations between the available $\mathrm{Zn}$ in soil and the uptake of $\mathrm{Cd}$ in roots and shoots of Z. mays $(p<0.05)$ further demonstrated the occurrence of competition for transfer protein between $\mathrm{Cd}$ and $\mathrm{Zn}$ (Cai et al. 2019).

\section{Conclusions}

This study investigated the influence of multiple washing operations on the removal efficiencies of heavy metals from an alkaline soil and the reuse strategy of the washed soil for safe agricultural production. According to the results, the removal percentages of $\mathrm{Cd}, \mathrm{Pb}, \mathrm{Cu}$ and $\mathrm{Zn}$ from the alkaline soil by MC were similar to those by EDTA. The highest 
removal efficiencies of heavy metals from all the treatments were obtained in the second washing. The multiple washing operations by pot experiment alleviated the change of physicochemical properties of the alkaline soil when compared our previous studies where used the combination of washing and shaking/stirring. The washing agents enhanced the transformation of relatively stable fractions of heavy metals to the unstable ones, which was not conducive to the agricultural reuse. After application of amendment, the soil washing operations had no obviously inhibition of the plant growth. Although the uptakes of heavy metals by shoots of Chinese cabbage had no significant difference when compared with the control, the heavy metals in the shoots of Z. mays (two batch) notably decreased and meet to the Hygienical Standard for Feeds of China (GB 13078 - 2017). When compared with the soil from EDTA treatment, the available heavy metals in the soil from MC treatment were significantly decreased after three-seasons harvests. Therefore, the multiple washing operation by $\mathrm{MC}$ is recommended for remediating alkaline soil that is heavily contaminated by heavy metals.

\section{Declarations}

Authors contributions Xiaofang Guo: Methodology, Original draft preparation, and funding, Yu Gao: Data analysis, graphic production, and writing, Wei Han: Experiment and data analysis, Guohui Zhao: Experiment and data analysis, Guixiang Zhang: Supervision, writing, reviewing and editing, Dandan Liu: Reviewing and editing

Funding This research is supported by the National Natural Science Foundation of China (No. 41401584) and the Natural Science Foundation of Shanxi Province (20210302123204).

Data Availability All data are true and valid and can be available.

Conflicts of interests The authors declare that we do not have any commercial or associative interest that represents a conflict of interest in connection with the work submitted.

Ethics approval I would like to declare on behalf of my co-authors that the work described was original research that has not been published previously.

Consent to participate All the authors listed consent to participate

Consent for publication All the authors listed have approved the manuscript that is enclosed.

\section{References}

1. Alberto F, Massimiliano F, Eric D, Giovanni E, Francesco P (2015) Effect of soil/contamination characteristics and process operational conditions on aminopolycarboxylates enhanced soil washing for heavy metals removal: a review. Reviews in Environmental Science and Bio/Technology 15:111-145

2. Begum ZA, Rahman I, Ishii K, Tsukada H, Hasegawa H (2020) Dynamics of Strontium and geochemically correlated elements in soil during washing remediation with eco-complaint chelators. Journal of Environmental Management 259: 110018

3. Beiyuan J, Lau AYT, Tsang DCW, Zhang W, Li XD (2018) Chelant-enhanced washing of CCA-contaminated soil: coupled with selective dissolution or soil stabilization. Science of the Total Environment 612: 1463-1472

4. Cai YM, Xu WB, Wang M, Chen W, Li X, Li Y, Cai Y (2019) Mechanisms and uncertainties of Zn supply on regulating rice Cd uptake. Environmental Pollution 253: 959-965

5. Chaturvedi R, Favas P, Pratas J, Varun M, Paul MS (2019) EDTA-Assisted Metal Uptake in Raphanus sativus L. and Brassica oleracea L.: Assessment of Toxicity and Food Safety. Bulletin of Environmental Contamination and 
Toxicology 103:490-495

6. Chen CL, Tian T, Wang MK, Wang G (2016) Release of Pb in soils washed with various extractants. Geoderma 275: 74-81

7. Chen NY, Zheng YJ, He XF (2014) National Soil pollution survey Bulletin. Journal of Agro-Environment Science 0: $1689-1692$

8. Chen ZJ, Xiao TF, Liu YZ, Xin D, Yang J, Zhu ZJ, Ning ZP (2021) Accumulation characteristics of heavy metals in agricultural soils and maize in a typical black shale area with high geochemical background. Chinese Journal of Ecology 40: 2315-2323

9. Chen ZL, Lei GJ, Su YM, Xiao F (2015) Effects of EDTA, Saponin on the Speciation of the Metal Forms of Pb and $\mathrm{Zn}$ in Complexly-Contaminated Soils. Ecology and Environmental Sciences 24: 1394-1398

10. Cheng J, Yuan CY, Zhang HY, Mao ZQ, Zhu HW, Wang YM, Li YZ (2021) Characteristics of heavy metal pollution in soils of Yunnan-Guizhou phosphate ore areas and their effects on quality of agricultural products. Journal of Ecology and Rural Environment 37: 636-643

11. Etesami $H$ (2018) Bacterial mediated alleviation of heavy metal stress and decreased accumulation of metals in plant tissues: mechanisms and future prospects. Ecotoxicology and Environmental Safety 147: 175-191

12. Finzgar N, Lestan D (2007) Multi-step leaching of Pb and Zn contaminated soils with EDTA. Chemosphere 66 : 824-832

13. Gluhar S, Jez E, Lestan D (2019a) The use of zero-valent Fe for curbing toxic emissions after EDTA-based washing of $\mathrm{Pb}, \mathrm{Zn}$ and $\mathrm{Cd}$ contaminated calcareous and acidic soil. Chemosphere 215(JAN.): 482-489

14. Gluhar S, Kaurin A, Grubar T, Prosen H, Lestan D (2019b) Dissipation of mecoprop-P, isoproturon, bentazon and Smetolachlor in heavy metal contaminated acidic and calcareous soil before and after EDTA-based remediation. Chemosphere 237:124513

15. Gluhar S, Kaurin A, Lestan D (2020) Soil washing with biodegradable chelating agents and EDTA: Technological feasibility, remediation efficiency and environmental sustainability. Chemosphere 257: 127226

16. Guo XF, Han W, Zhang GX, Yang Y, Wu QT (2020a) Effect of inorganic and organic amendments on maize biomass, heavy metals uptake and their availability in calcareous and acidic washed soil. Environmental Technology \& Innovation 19: 101038

17. Guo XF, Han W, Zhao GH, Zhang GX, He QS (2020b) Effects of mixed chelators on the removal of heavy metals from contaminated soil and on the growth of plants. Journal of Agro-Environment Science 39: 1486-1493

18. Guo XF, Wei ZB, Penn CJ, Xu TF, Wu QT (2013) Effect of soil washing and liming on bioavailability of heavy metals in acid contaminated soil. Soil Science Society of America Journal 77: 432-441

19. Guo XF, Wei ZB, Xue JH, Zhang LP, Wu QT (2017) Effects of Lime Solution on Mixture of Chelators Extraction of Heavy Metals from Contaminated Soil. Soils 49(1): 129-134

20. Guo XF, Yang YH, Ji L, Zhang G, He QS, Wei ZB, Qian TW, Wu QT (2019) Revitalization of Mixed Chelator-Washed Soil by Adding of Inorganic and Organic Amendments. Water Air and Soil Pollution 230: 112

21. Guo XF, Zhang GX, Wei ZB, Zhang L, He QS, Wu QT, Qian TW (2018a) Mixed chelators of EDTA, GLDA, and citric acid as washing agent effectively remove $\mathrm{Cd}, \mathrm{Zn}, \mathrm{Pb}$ and $\mathrm{Cu}$ from soils. Journal of Soil and Sediment 18: 835-844

22. Guo XF, Zhao GH, Zhang GX, He QS, Wu QT (2018b) Effect of mixed chelators of EDTA, GLDA, and citric acid on bioavailability of residual heavy metals in soils and soil properties. Chemosphere 209: 776-782

23. Hazrati S, Farahbakhsh M, Heydarpoor G, BesalatpourAA (2020) Mitigation in availability and toxicity of multimetal contaminated soil by combining soil washing and organic amendments stabilization. Ecotoxicology and Environmental Safety 201:110807

Page $11 / 21$ 
24. Hu P, Yang B, Dong C, Chen L, Cao X, Zhao J, Wu L, Luo Y, Christie P (2014) Assessment of EDTA heap leaching of an agricultural soil highly contaminated with heavy metals. Chemosphere 117(1): 532-537

25. Jean-Soro L, Bordas F, Bollinger JC (2012) Column leaching of chromium and nickel from a contaminated soil using EDTA and citric acid. Environmental Pollution 164: 175-181

26. Jelusic M, Vodnik D, Lestan D (2014) Revitalization of EDTA-remediated soil by fertilization and soil amendments. Engineering Economist 73: 429-438

27. Jia MY, Yu JP, Li Z, Wu LH, Christie P (2021) Effects of biochar on the migration and transformation of metal species in a highly acid soil contaminated with multiple metals and leached with solutions of different $\mathrm{pH}$. Chemosphere 130344

28. Jiang L, Xing HL, Zhang Y (2003) Engineering Chemistry. Beijing: Chemical Industry Press

29. Jing Z, Bei Y, Daniel M, Zhang W, Yang X, Ok YS, Li XD (2017) Selective dissolution followed by EDDS washing of an e-waste contaminated soil: Extraction efficiency, fate of residual metals, and impact on soil environment. Chemosphere 166: 489-496

30. Kaurin A, Gluhar S, Tilikj N, Lestan D (2020) Soil washing with biodegradable chelating agents and EDTA: Effect on soil properties and plant growth. Chemosphere 260: 127673

31. Klik B, Gusiatin ZM, Kulikowska D (2021) A holistic approach to remediation of soil contaminated with $\mathrm{Cu}, \mathrm{Pb}$ and $\mathrm{Zn}$ with sewage sludge-derived washing agents and synthetic chelator. Journal of Cleaner Production 311: 127664

32. Li YQ, Wang YJ, Khan MAK, Luo WL, Xiang ZC, Xu WJ, Zhong B, Ma JW, Ye ZQ, Zhu YW, Duan LL, Liu D (2021) Effect of plant extracts and citric acid on phytoremediation of metal-contaminated soil. Ecotoxicology and Environmental Safety 211: 111902

33. Liu CC, Lin YC (2013) Reclamation of copper-contaminated soil using EDTA or citric acid coupled with dissolved organic matter solution extracted from distillery sludge-ScienceDirect. Environmental Pollution 178: 97-101

34. Liu Q, Deng Y, Tang J, Chen D, Li X, Lin Q, Yin G, Zhang M, Hu H (2019) Potassium lignosulfonate as a washing agent for remediating lead and copper co-contaminated soils. Science of the Total Environment 658: 836-842

35. Liu X, Liu XW, Wu YX, Li J, Ren J, Liang PX, Zhang HX, Li YL (2020) Review on phytoextraction of heavy metals from contaminated agricultural land. Environmental Pollution \& Control 42: 507-513

36. Lu RK (2000) Analytical Methods of Soil Agrochemistry. China Agriculture Science Technology Press Beijing (in Chinese)

37. Ma YJ, Wang YT, Chen Q, Li YS, Guo DC, Nie XH, Peng XY (2020) Assessment of heavy metal pollution and the effect on bacterial community in acidic and neutral soils. Ecological Indicators 117(1): 106626

38. Manouchehri N, Besancon S, Bermond A (2006) Major and trace metal extraction from soil by EDTA: Equilibrium and kinetic studies. Analytica Chimica Acta 559(1):105-112

39. Mikel A, Carlos G, Oihane S, Lur E, Itziar A, Miren MS (2022) Acidification alters the functionality of metal polluted. Applied Soil Ecology 163

40. Nejad ZD, Jung MC, Kim KH (2017) Remediation of soils contaminated with heavy metals with an emphasis on immobilization technology. Environmental Geochemistry \& Health 40: 927-953

41. Orr R, Hocking RK, Pattison A, Nelson PN (2020) Extraction of metals from mildly acidic tropical soils: Interactions between chelating ligand, $\mathrm{pH}$ and soil type. Chemosphere 248: 126060

42. Peng YP, Chang YC, Chen KF, Wang CH (2020) A field pilot-scale study on heavy metal-contaminated soil washing by using an environmentally friendly agent-poly- $\gamma$-glutamic acid ( $\gamma-P G A)$. Environmental Science and Pollution Research 27:34760-34769

Page $12 / 21$ 
43. Polettini A, Pomi R, Rolle E (2007) The effect of operating variables on chelant-assisted remediation of contaminated dredged sediment. Chemosphere 66: 866-877

44. Qi HD, Guo Z, Lu S, Li YG, Yang HL (2019) Effect of Sodium Citrate on Zn-Ni-Mn Alloy Electrodeposition Behavior. Surface Technology 48: 201-210

45. Shahid M, Pinelli E, Dumat C (2012) Review of Pb availability and toxicity to plants in relation with metal speciation; role of synthetic and natural organic ligands. Journal of Hazardous Materials 219-220:1-12

46. Spana H, Bas F, Zornoza R, Gandarillas M, Arellano E, Ginocchio R (2019) Effectiveness of pig sludge as organic amendment of different textural class mine tailings with different periods of amendment-contact time. Journal of Environmental Management 230:311-318

47. State of China's Ecological Environment (Excerpt, 2021). Environmental protection 49: 47-68

48. Sun TM, Ji YN, Li K (2020) The speciation distributions of heavy metals in weakly alkaline maize soils and its potential ecological risk. Environmental Chemistry 39(9): 2469-2478

49. Tang Z, Zhang L, Huang Q, Yang Y, Nie Z, Cheng J, Yang J, Wang Y, Chai M (2015) Contamination and risk of heavy metals in soils and sediments from a typical plastic waste recycling area in North China. Ecotoxicology and Environment Safe 122(DEC.): 343-351

50. Tessier A, Campbell PGC, Bisson M (1979) Sequential extraction procedure for the spciation of particulate trace metal. Analytical Chemistry 51: 844-851

51. Thinh NV, Osanai Y, Adachi T, Vuong BTS, Thai PK (2020) Removal of lead and other toxic metals in heavily contaminated soil using biodegradable chelators: GLDA, citric acid and ascorbic acid. Chemosphere 263:127912

52. Udovic M, Lestan D (2012) EDTA and HCl leaching of calcareous and acidic soils polluted with potentially toxic metals: Remediation efficiency and soil impact. Chemosphere 88(6):718-724

53. Wang G, Pan X, Zhang S, Zhong Q, Peijnenburg WJGM (2020a) Remediation of heavy metal contaminated soil by biodegradable chelator-induced washing: Efficiencies and mechanisms. Environmental Research 186:109554

54. Wang G, Zhang S, Zhong Q, Xu X, Li T, Jia Y, Zhang Y, Peijnenburg WJGM, Vijver MG (2018a) Effect of soil washing with biodegradable chelators on the toxicity of residual metals and soil biological properties. Science of the Total Environment 625: 1021-1029

55. Wang GY, Zhang SR, Zhong QM, Peijnenburg WJGM, Vijver MG (2018b) Feasibility of Chinese cabbage (Brassica bara) and lettuce (Lactuca sativa) cultivation in heavily metals-contaminated soil after washing with biodegradable chelators. Journal of Cleaner Production 197: 479-490

56. Wang H, Cheng MN, Sun TS (2021) Study on the remediation of Cd contaminated soil in Dam-Break area with Conyza Canadensis L. under enhanced organic fertilizer or EDTA conditions. Journal of Shanxi Agricultural University (Natural Science Edition) 41: 95-102

57. Wang ZN, Jia MY, Li Z, Liu HY, Christie P, Wu LH (2020b) Acid buffering capacity of four contrasting metalcontaminated calcareous soil types: Changes in soil metals and relevance to phytoextraction. Chemosphere 256:127045

58. Wei ZB, Chen XH, Wu QT, Tan M (2015) Enhanced phytoextraction of heavy metals from contaminated soils using sedum alfredii hance with biodegradable chelate GLDA. Environmental Science 36: 1864-1869

59. Wei ZB, Guo XF, Wu QT, Chen XH (2016) Effects of different application methods of mixed chelators on remediation of heavy metal contaminated soil in interplanting system. Journal of South China Agricultural University 37(01):29-34

60. Wu JH, Song QM, Zhou JY, Wu YX, Liu XW, Liu JJ, Zhou LL, Wu ZH, Wu WC (2020) Cadmium threshold for acidic and multi-metal contaminated soil according to Oryza sativa L. Cadmium accumulation: Influential factors and 
prediction model. Ecotoxicology and Environmental Safety 208

61. Wu Q, Cui YR, Tang XX, Yang HJ, Sun JH (2015) Extraction of Heavy Metals from Sludge Using Biodegradable Chelating Agent N,N-bis(carboxymethyl) Glutamic Acid Tetrasodium. Environmental Science 36(5):1733-1738

62. Xiao R, Ali A, Wang P, Li R, Tian X, Zhang Z (2019) Comparison of the feasibility of different washing solutions for combined soil washing and phytoremediation for the detoxification of cadmium (Cd) and zinc ( $\mathrm{Zn})$ in contaminated soil. Chemosphere 230: 510-518

63. Xue QH, Huang FL, Liang F, Guo ZH (2019) Continuous soil washing with EDTA/DTPA combined with citric acid for removing $\mathrm{Cd}$ and $\mathrm{Pb}$ and its impact on soil fertility. Mining and Metallurgical Engineering 39(05):74-78

64. Yadav P, Kaur R, Kanwar MK, Sharma A, Verma V, Sirhindi G, Bhardwaj R (2018) Castasterone confers copper stress tolerance by regulating antioxidant enzyme responses, antioxidants, and amino acid balance in $\mathrm{B}$. juncea seedlings. Ecotoxicology and Environmental Safety 147: 725-734

65. Yan DM, Zhao HG, Xiao XY, Peng C, He YL, Yang AD, Wang XY, Hu YL, Li ZH (2021) Cleanup of arsenic, cadmium, and lead in the soil from a smelting site using N, N-bis(carboxymethyl)-L-glutamic acid combined with ascorbic acid: A lab-scale experiment. Journal of Environmental Management 296: 113174

66. Yang J, Wang J, Li JY, Li H (2016) Discussion on heavy metals removal efficiency in clay by soil washing. Environmental Science \& Technology 39: 294-298

67. Yang YH (2019) Study on the combination of soil washing and chemical amendment to remediate heavy metal contaminated soil. Dissertation, Taiyuan University of science and technology

68. Yoo J, Beiyuan J, Wang L, Tsang DCW, Baek K, Bolan NS, Ok YS, Li XD (2018) A combination of ferric nitrate/EDDS-enhanced washing and sludge-derived biochar stabilization of metal-contaminated soils. Science and Total Environmental 616-617: 572-582

69. Zeng F, Ali S, Zhang H, OuyangY, Qiu B, Wu F, Zhang G (2011) The influence of pH and organic matter content in paddy soil on heavy metal availability and their uptake by rice plants. Environmental Pollution 159(1): 84-9

70. Zhai X, Li Z, Huang B, Luo N, Huang M, Zhang Q, Zeng G (2018) Remediation of multiple heavy metalcontaminated soil through the combination of soil washing and in situ immobilization. Science of the Total Environment 635: 92-99

71. Zhao GH (2019) The study of agricultural production of heavy metal contaminated soil after chemical washing and treatment of spent solution after soil washing. Dissertation, Taiyuan University of science and technology

72. Zhou K, Huangpu ZX, Zhong CP, Ding P, Xie SQ, Yu J (2021) The biodegradable chelate GLDA enhanced phytoextraction for cadmium-contaminated soil. Environmental Engineering 39: 165-170

73. Zupanc V, Kastelec D, Lestan D, Grcman H (2014a) Soil physical characteristics after EDTA washing and amendment with inorganic and organic additives. Environmental Pollution 186: 56-62

74. Zupanc V, Kastelec D, Lestan D, Grcman H (2014b) Soil physical characteristics after EDTA washing and amendment with inorganic and organic additives. Environment Pollution 186: 56-62

\section{Tables}

Table 1 The design of washing times 


\begin{tabular}{|lllllllll|}
\hline Treatments & \multicolumn{9}{l}{ Soil washing times } & & & & \\
\cline { 2 - 8 } & first & second & third & fourth & fifth & sixth & seventh \\
\hline Control treatment & DW $^{\text {a }}$ & DW & DW & DW & DW & DW & DW \\
MC treatment & MC $^{b}$ & MC & DW & DW & MC & DW & DW \\
\hline EDTA treatment & EDTA $^{c}$ & EDTA & DW & DW & EDTA & DW & DW \\
\hline
\end{tabular}

a DW, Deionized water $(0.55 \mathrm{~L})$

b MC, Mixture of chelators $(0.55 \mathrm{~L})$

c EDTA, $(0.55 \mathrm{~L})$

Table 2 The basic physiochemical properties and heavy metal contents in different soils

\begin{tabular}{|lllll|}
\hline Parameter & Original soil & Control soil & MC-washed & EDTA-washed \\
\hline $\mathrm{pH}$ & $8.36 \pm 0.01 \mathrm{a}$ & $8.56 \pm 0.04 \mathrm{a}$ & $9.94 \pm 0.18 \mathrm{~b}$ & $9.71 \pm 0.20 \mathrm{~b}$ \\
\hline Organic matter $\left(\mathrm{g}^{\mathrm{k}} \mathrm{kg}^{-1}\right)$ & $31.3 \pm 0.0 \mathrm{a}$ & $31.6 \pm 0.8 \mathrm{a}$ & $33.2 \pm 0.3 \mathrm{~b}$ & $34.8 \pm 1.1 \mathrm{~b}$ \\
\hline Total nitrogen $\left(\mathrm{g} \mathrm{kg}^{-1}\right)$ & $3.78 \pm 0.69 \mathrm{a}$ & $3.46 \pm 0.30 \mathrm{a}$ & $4.38 \pm 0.45 \mathrm{a}$ & $3.92 \pm 0.60 \mathrm{a}$ \\
\hline Total phosphorus $\left(\mathrm{g} \mathrm{kg}^{-1}\right)$ & $0.66 \pm 0.00 \mathrm{~b}$ & $0.61 \pm 0.01 \mathrm{~b}$ & $0.60 \pm 0.01 \mathrm{~b}$ & $0.42 \pm 0.36 \mathrm{a}$ \\
\hline Total potassium $\left(\mathrm{g} \mathrm{kg}^{-1}\right)$ & $19.6 \pm 3.3 \mathrm{~b}$ & $15.0 \pm 1.3 \mathrm{a}$ & $13.8 \pm 1.6 \mathrm{a}$ & $14.4 \pm 4.2 \mathrm{a}$ \\
\hline Available nitrogen $\left(\mathrm{mg} \mathrm{kg}^{-1}\right)$ & $78.8 \pm 0.0 \mathrm{a}$ & $78.8 \pm 4.6 \mathrm{a}$ & $130.7 \pm 9.6 \mathrm{~b}$ & $84.0 \pm 9.9 \mathrm{a}$ \\
\hline Available phosphorus $\left(\mathrm{mg} \mathrm{kg}^{-1}\right)$ & $17.6 \pm 0.0 \mathrm{a}$ & $16.6 \pm 0.5 \mathrm{a}$ & $23.8 \pm 1.5 \mathrm{~b}$ & $24.1 \pm 1.0 \mathrm{~b}$ \\
\hline Available potassium $\left(\mathrm{mg} \mathrm{kg}^{-1}\right)$ & $203.1 \pm 0.0 \mathrm{~b}$ & $181.0 \pm 6.9 \mathrm{a}$ & $173.2 \pm 6.0 \mathrm{a}$ & $177.4 \pm 6.3 \mathrm{a}$ \\
\hline Cation exchange capacity $\left(\mathrm{cmol} \mathrm{kg}{ }^{-1}\right)$ & $42.9 \pm 0.6 \mathrm{~b}$ & $43.4 \pm 1.3 \mathrm{bc}$ & $41.0 \pm 0.6 \mathrm{a}$ & $44.7 \pm 1.0 \mathrm{c}$ \\
\hline Total Cd $\left(\mathrm{mg} \cdot \mathrm{kg}^{-1}\right)$ & $19.2 \pm 0.3 \mathrm{a}$ & $20.6 \pm 0.6 \mathrm{a}$ & $11.7 \pm 1.4 \mathrm{~b}$ & $8.9 \pm 0.8 \mathrm{c}$ \\
\hline Total Pb $\left(\mathrm{mg} \cdot \mathrm{kg}^{-1}\right)$ & $373 \pm 8 \mathrm{a}$ & $293 \pm 8 \mathrm{a}$ & $172 \pm 9 \mathrm{~b}$ & $108 \pm 9 \mathrm{~b}$ \\
\hline Total Cu $\left(\mathrm{mg} \cdot \mathrm{kg}^{-1}\right)$ & $67.6 \pm 1.2 \mathrm{a}$ & $70.9 \pm 2.4 \mathrm{a}$ & $60.2 \pm 1.4 \mathrm{~b}$ & $53.6 \pm 8.7 \mathrm{c}$ \\
\hline Total Zn $\left(\mathrm{mg} \cdot \mathrm{kg}^{-1}\right)$ & $970 \pm 13 \mathrm{a}$ & $964 \pm 22 \mathrm{a}$ & $621 \pm 1 \mathrm{~b}$ & $597 \pm 24 \mathrm{~b}$ \\
\hline
\end{tabular}

Note: The values in the table are mean \pm Standard deviation $(n=3)$, according to Duncan's multiple range test $(p<$ $0.05)$, the means in the same line followed by the same letter were not significantly different.

Table 3 Yields $\left(\mathrm{g} \cdot \mathrm{pot}^{-1}\right)$ of plants and heavy metal contents $\left(\mathrm{mg} \cdot \mathrm{kg}^{-1}\right)$ in plants in the soils from different treatments. 


\begin{tabular}{|c|c|c|c|c|c|c|c|}
\hline \multicolumn{2}{|c|}{ Parameters } & \multicolumn{3}{|l|}{ Aboveground } & \multicolumn{3}{|l|}{ Underground } \\
\hline & & Control & $\mathrm{MC}$ & EDTA & Control & $\mathrm{MC}$ & EDTA \\
\hline \multirow{5}{*}{$\begin{array}{l}\text { Chinese } \\
\text { cabbage }\end{array}$} & Fw & $17.05 \pm 2.93 a$ & $19.32 \pm 0.96 a$ & $19.23 \pm 1.64 a$ & $0.26 \pm 0.08 a$ & $0.22 \pm 0.07 a$ & $0.24 \pm 0.09 a$ \\
\hline & $\mathrm{Cd}$ & $1.49 \pm 0.07 a$ & $1.78 \pm 0.37 a$ & $1.51 \pm 0.52 a$ & $2.52 \pm 0.50 a$ & $13.45 \pm 3.80 b$ & $1.10 \pm 0.22 a$ \\
\hline & $\mathrm{Pb}$ & $0.45 \pm 0.08 a$ & $0.62 \pm 0.07 b$ & $0.74 \pm 0.13 b$ & $3.54 \pm 1.44 a$ & $20.48 \pm 0.67 b$ & $53.15 \pm 5.36 c$ \\
\hline & $\mathrm{Cu}$ & $5.34 \pm 0.51 a$ & $5.35 \pm 0.48 a$ & $6.01 \pm 2.79 a$ & $25.44 \pm 4.64 a$ & $32.87 \pm 1.29 b$ & $47.98 \pm 1.84 c$ \\
\hline & $\mathrm{Zn}$ & $19.13 \pm 2.22 b$ & $18.93 \pm 2.37 b$ & $13.31 \pm 3.83 a$ & $76.14 \pm 8.55 a$ & $131.51 \pm 14.91 b$ & $62.34 \pm 15.34 a$ \\
\hline \multirow{5}{*}{$\begin{array}{l}\text { Z. mays } \\
\text { (batch1) }\end{array}$} & Dw & $0.45 \pm 0.13 a$ & $0.48 \pm 0.06 a$ & $0.41 \pm 0.13 a$ & $0.07 \pm 0.02 a$ & $0.08 \pm 0.01 a$ & $0.07 \pm 0.06 a$ \\
\hline & $\mathrm{Cd}$ & $0.86 \pm 0.08 b$ & $0.41 \pm 0.00 a$ & $0.38 \pm 0.09 a$ & $5.67 \pm 0.38 c$ & $1.63 \pm 0.05 b$ & $1.02 \pm 0.35 a$ \\
\hline & $\mathrm{Pb}$ & $0.25 \pm 0.13 a$ & $0.70 \pm 0.34 a$ & $1.12 \pm 1.38 a$ & $0.25 \pm 0.13 a$ & $0.70 \pm 0.34 a$ & $1.12 \pm 1.38 a$ \\
\hline & $\mathrm{Cu}$ & $1.62 \pm 0.05 a$ & $1.49 \pm 0.24 a$ & $1.62 \pm 0.15 a$ & $4.30 \pm 1.11 a$ & $3.99 \pm 0.70 a$ & $4.23 \pm 0.70 a$ \\
\hline & $\mathrm{Zn}$ & $23.84 \pm 0.84 c$ & $14.10 \pm 2.21 \mathrm{a}$ & $18.40 \pm 0.20 b$ & $46.63 \pm 5.17 b$ & $13.53 \pm 7.51 a$ & $6.58 \pm 0.53 a$ \\
\hline \multirow{5}{*}{$\begin{array}{l}\text { Z. mays } \\
\text { (batch2) }\end{array}$} & Dw & $1.34 \pm 0.14 a$ & $1.09 \pm 0.35 a$ & $0.98 \pm 0.54 a$ & $0.37 \pm 0.09 a$ & $0.24 \pm 0.16 a$ & $0.16 \pm 0.17 a$ \\
\hline & $\mathrm{Cd}$ & $0.36 \pm 0.03 a$ & $0.26 \pm 0.04 a$ & $0.29 \pm 0.13 a$ & $1.57 \pm 0.18 c$ & $0.77 \pm 0.15 b$ & $0.32 \pm 0.21 a$ \\
\hline & $\mathrm{Pb}$ & $0.14 \pm 0.02 a$ & $0.44 \pm 0.01 a b$ & $1.03 \pm 0.83 c$ & $2.64 \pm 0.65 b$ & $1.08 \pm 0.24 a$ & $2.10 \pm 0.38 b$ \\
\hline & $\mathrm{Cu}$ & $0.84 \pm 0.09 a$ & $1.58 \pm 0.09 c$ & $1.25 \pm 0.15 b$ & $3.96 \pm 0.84 a$ & $2.37 \pm 0.48 a$ & $7.47 \pm 6.74 a$ \\
\hline & $\mathrm{Zn}$ & $14.79 \pm 0.35 a$ & $14.23 \pm 2.56 \mathrm{a}$ & $16.27 \pm 7.77 a$ & $6.31 \pm 1.87 a$ & $36.17 \pm 10.86 b$ & $9.26 \pm 7.23 a$ \\
\hline
\end{tabular}

Note: FW, Fresh weight; DW, Dry weight.

\section{Figures}



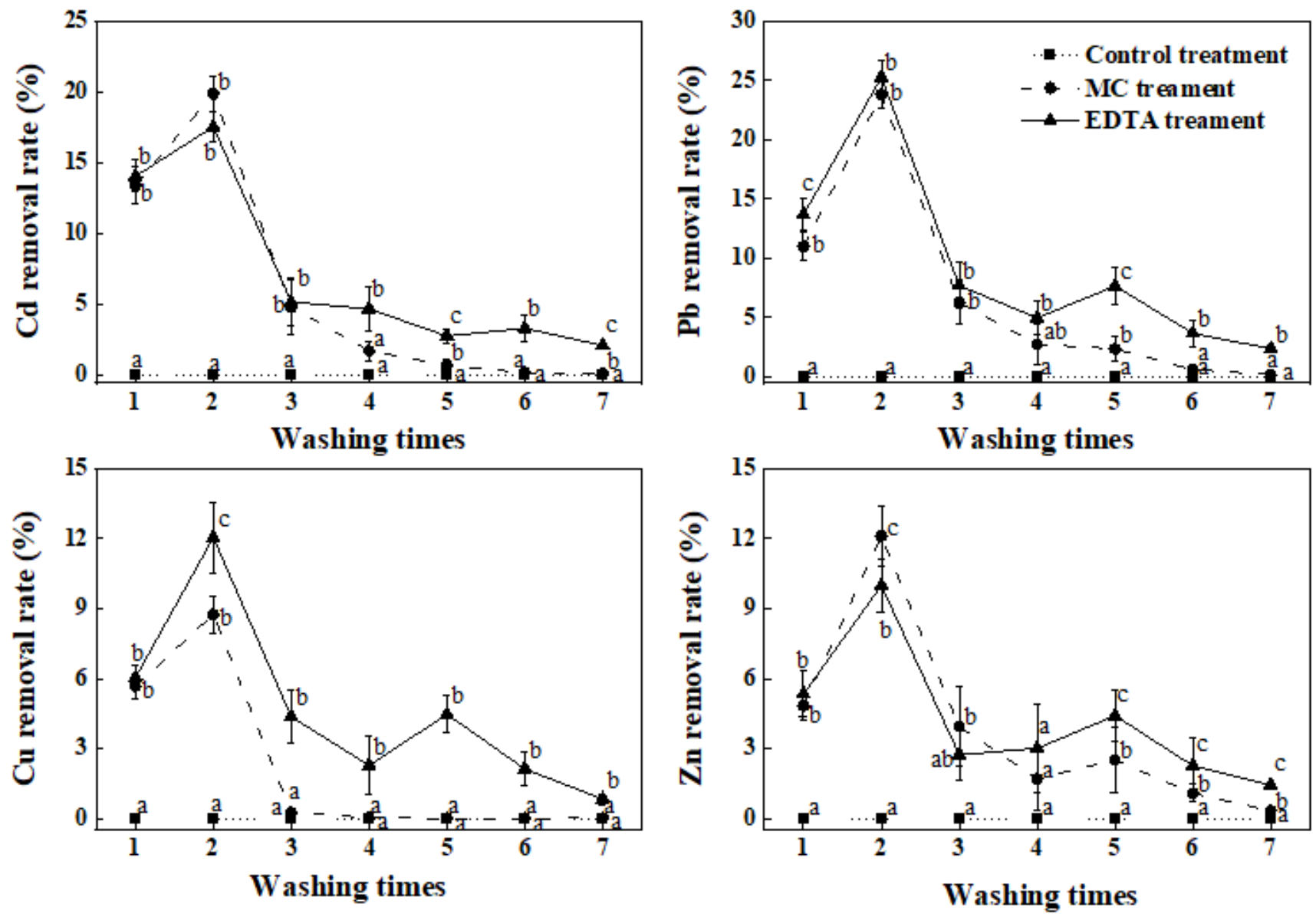

Fig. 1

Figure 1

Effect of different treatments on the removal efficiencies of heavy metals in the contaminated soil. 


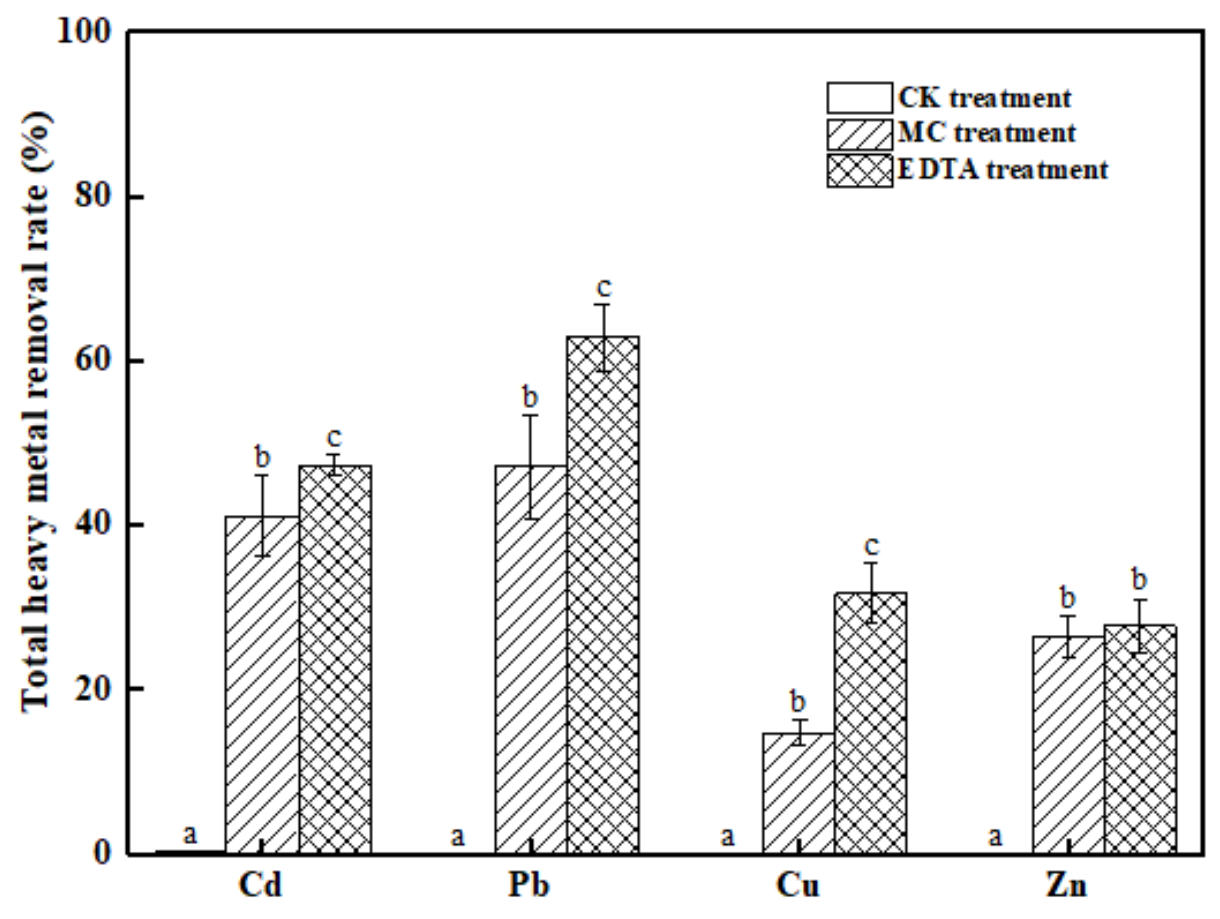

Fig. 2

Figure 2

The total removal efficiencies of heavy metals from the contaminated soil by washing. 

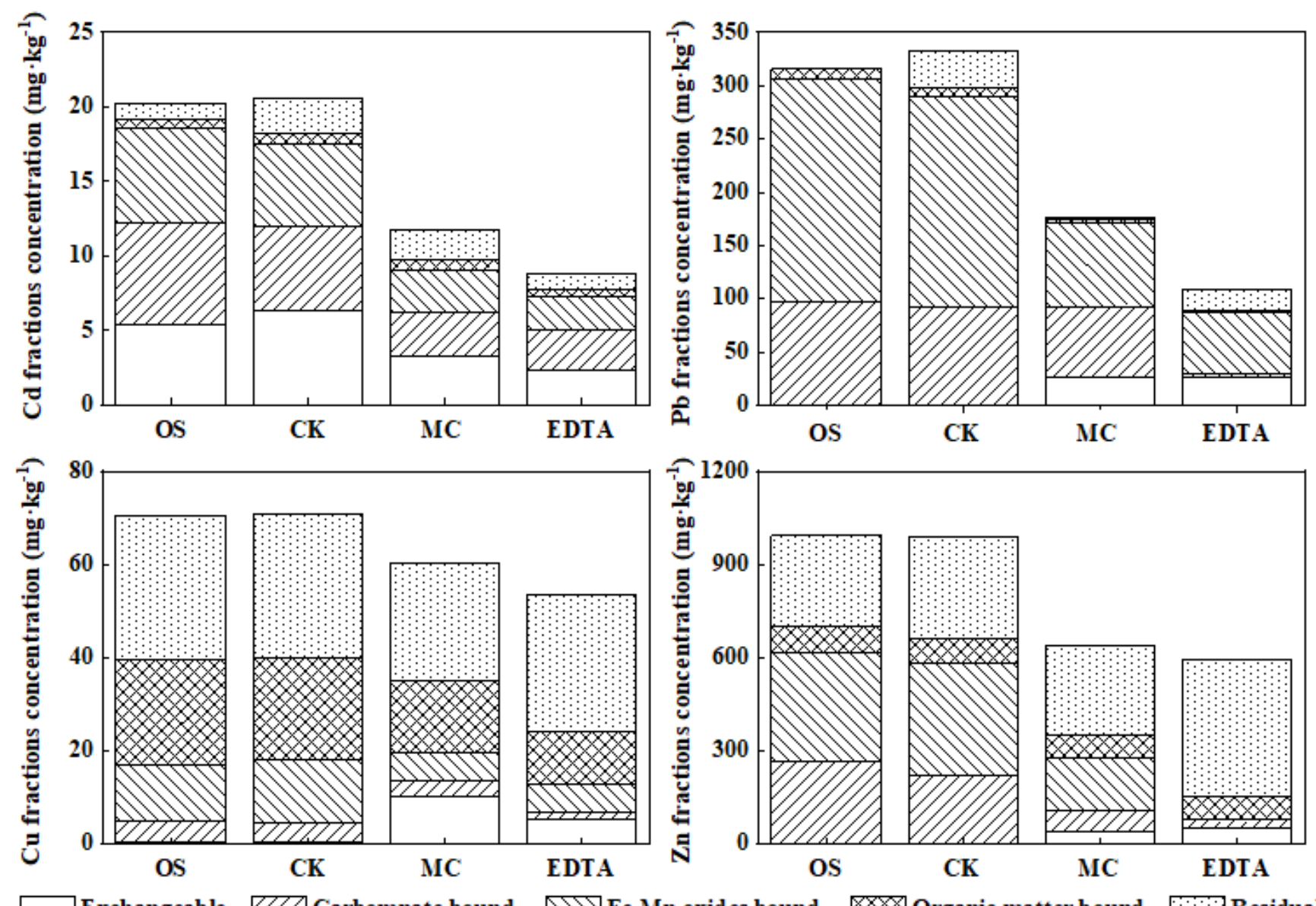

Exchangeable $Z / Z$ Carbomnate bound $\triangle M$ Fe-Mn oxides bound Organic matter bound Residual

Fig. 3

Figure 3

Effect of different treatments on the changes in fractions of heavy metals in soil (OS: Original soil; CK: Control treatment; MC: MC treatment; EDTA: EDTA treatment) 

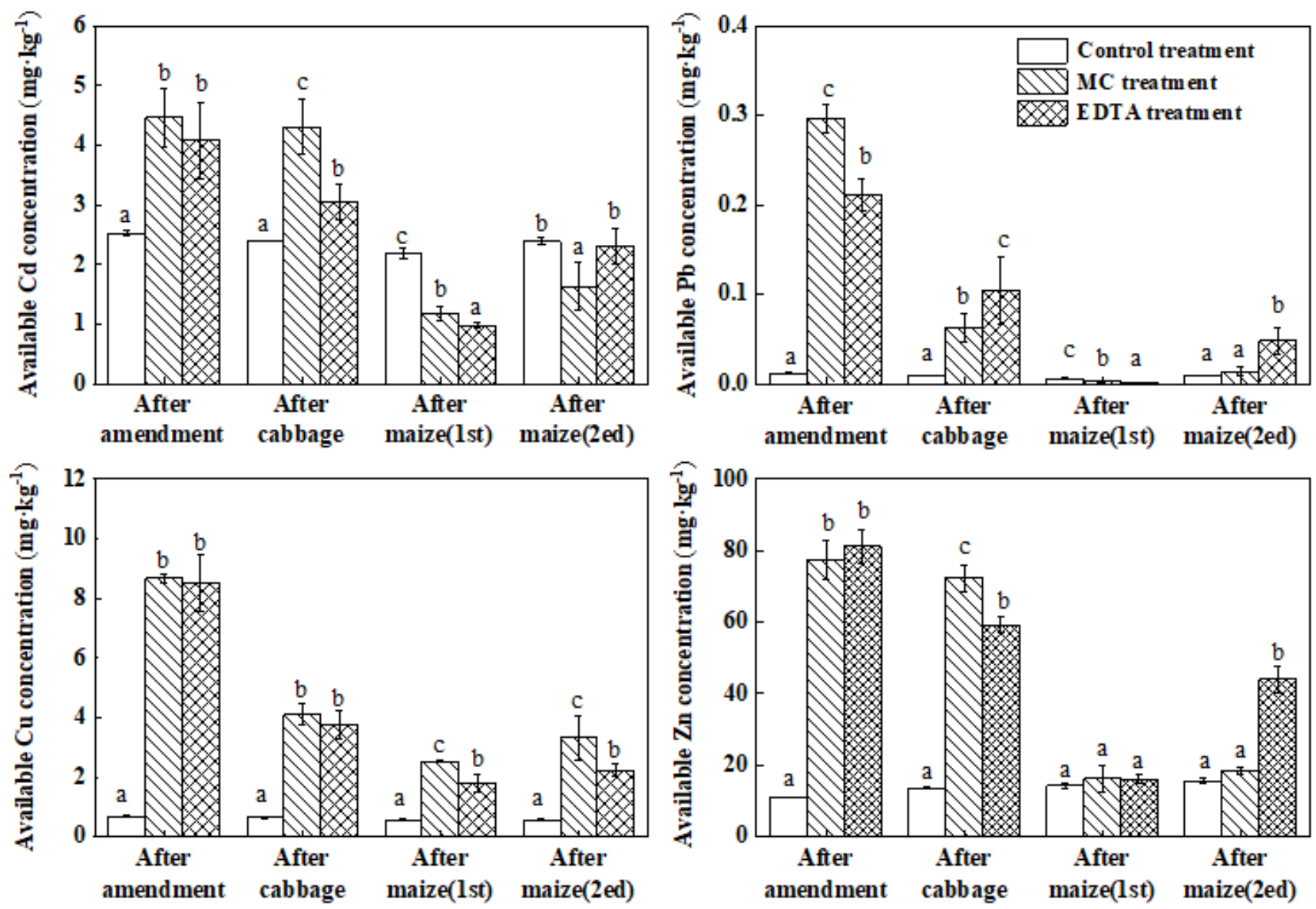

Fig. 4

Figure 4

Effect of different treatments and washing times on $\mathrm{NH}_{4} \mathrm{Ac}$-extracted heavy metals in soil. 


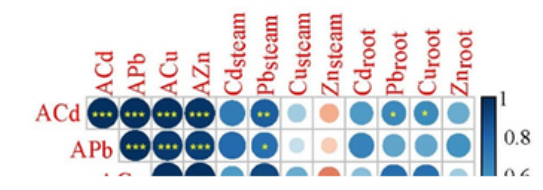

\section{Figure 5}

Correlations between the $\mathrm{NH}_{4} \mathrm{Ac}$-extracted heavy metals and the uptake of heavy metals by plants (A, Chinese cabbage; B, batch 1 Z. mays, C, batch 2 Z. mays) .

\section{Supplementary Files}

This is a list of supplementary files associated with this preprint. Click to download.

- Graphicalabstract.png 